\title{
The Right Report from the Right Source at the Right Time - The National Academies of Sciences, Engineering, and Medicine (NASEM) Primary Care Report
}

\author{
Marjorie A. Bowman, MD, MPA, Dean A. Seebusen, MD, MPH, and \\ Christy J. W. Ledford, PhD
}

( J Am Board Fam Med 2021;34:886-887.)

In May 2021, the National Academies of Sciences, Engineering, and Medicine (NASEM) collectively amplified the potential of high-quality primary care as a solution to a disparate, fractured health care system. ${ }^{1}$ This solution can lower costs, improve utilization patterns, and reduce mortality. The comprehensive, well-written, intensely referenced consensus report refines the definition of primary care and outlines an implementation plan. NASEM refocuses primary care in the context of relationships, signaling that the foundation of quality care is people, not science and systems.

Our discipline has been a leader in improving primary care in the United States. As family physicians, we provide first contact, comprehensive, whole-person, and family care across the life course. In our practice, we inherently know and signal our focus on people. However, many of us have experienced the recurrent defeat that accompanies attempts to increase access to and recognition of the importance of primary care. The situation in the United States is stagnant-either the same or worse overall for the public than in the past. Yet, from personal attempts or our experience with patients, we also know that behavior change takes multiple efforts over time, even after multiple relapses. Perhaps Coronavirus disease 2019 (COVID-19) and the NASEM report together are catalysts for sustained behavior change to full access to primary care for all in the United States.

The NASEM committee posits that primary care is a common good, like clean air, safe drinking water, and public transportation. As a monolith, the

Conflict of interest: The authors are editors of the $7 A B F M$. current system, with little argument, can provide amazing, world-renown care for Americans with money and insurance. Science provides mind-boggling innovation and potential every second. But in our communities, many people go without care. COVID-19 has pulled back the curtain on what many family physicians have witnessed for decades: preventive care is a privilege. For our communities and patients without resources, basic diseases go undiscovered or untreated until the disease has already ravaged patients and their families' quality of life. While science is revered, human suffering is ignored. By labeling primary care a common good, the authors make a compelling argument that it is the government's responsibility to ensure primary care is (1) available to everyone, (2) affordable, and (3) high quality. In the context of current political debates occurring in the nation's capital, primary care is a scaffold in America's infrastructure. The lack of adequate primary care in the United States results from the general economic model, represents a mix of capitalism and socialism, and reflects an emphasis on individual health rather than collective, or public, health. The results are often ugly.

The report is not without its shortcomings. First, the strong emphasis on team-based care provides little application for the solo physician's office. Second, the lack of specialists and our other medical home neighbors among the report's authors will draw criticism from the organizations that represent various specialties. Despite these limitations, this report represents an important roadmap toward a better American health care system.

Now is the time to enact the recommendations of the report. Readers can argue with the proposed 
tactics among the 449 pages, but the overall goal and the major recommendations are focused and directed. Successful implementation will require many like-minded individuals at many levels of politics and power to move this forward. Our discipline, led by family medicine organizations, is already considering how to support the implementation of the NASEM recommendations most pertinent to our members and customers. We all play a part through advocating for patients; conducting research that powers the methods and evaluation of health services and patient care; assisting our organizations to increase their power; educating the future generations of clinicians on the importance of primary care, and most importantly, by providing high-quality primary care in our own communities.

$7 A B F M$ editors call on our colleagues to support the changes needed to increase and improve primary care for the benefit of our country and its people. Start with sharing the main ideas of this report within your own organization and your elected representatives, helping your organization and community understand what primary care is and what we can accomplish together. Work to get the report's recommendations incorporated into the strategic plan of your health system, regardless of its size. As a specialty, we must not allow this report to be an end product. Instead, let us treat it as the beginning of a conversation about making the American health care system better.

Part of our role in this effort is to facilitate the conversation about the consensus report. We invite you, our readers, to submit short commentaries or letters to the editor on the report and, just as importantly, to submit research reports that demonstrate evidence for steps to improve high-quality primary care for all Americans.

To see this article online, please go to: http://jabfm.org/content/ 34/5/886.full.

\section{Reference}

1. National Academies of Sciences, Engineering, and Medicine. 2021. Implementing bigh-quality primary care: Rebuilding the foundation of bealth care. Washington, DC: The National Academies Press. Available from: https://doi.org/10.17226/25983. 